PILGRIM'S PROGRESS

\title{
A STUDY OF THE RELATION BETWEEN ENDEMIC DISEASES AND TRAVEL AT INCREASING SPEED*
}

\author{
By Lieutenant-General Sir ROBERT DREW \\ K.C.B., C.B.E., M.B., F.R.C.P., F.R.C.P.E. \\ Director-General, Army Medical Services
}

FIRST I wish to thank the Council for its nomination and you the Fellows of this Society, for the honour which you have done me in electing me President for the ensuing year. To succeed those who have lately filled this Chair with such distinction is a challenge to the incoming President. I am naturally proud to have been given the opportunity and will serve you as best I can.

It was in 1767 , just six years before our Society began, that Lettsom sailed for the West Indies to revisit his birthplace on the Island of Tortola. He had decided to wind up his father's estate and to free the slaves. We know that he encountered tropical diseases there because he was called upon to treat a fellow medical practitioner with yellow fever, and to deal with a young woman in coma with remittent fever, the cause of which was probably malignant malaria.

Lettsom started practice in London in 1770 and two years later he published his book on fevers, based on a wide experience of smallpox, typhus, relapsing fever, dysentery and other diseases which were then prevalent in the city. Although he gave strong support to William Jenner and vaccination, there is evidence that his interest in the problems of immunity was not limited to smallpox. For example, he wrote to Dr. Benjamin Rush of yellow fever fame, enquiring if one attack protected an individual from the disease. Rush, then Professor of Medicine in the University of Pennsylvania, replied that he knew at least one hundred patients who had suffered second attacks. It was later, in 1784, that Rush was elected a corresponding member of this Society.

Lettsom observed that typhus, or gaol fever, was a disease of the poor, less prevalent in the more salubrious parts of the city where housing, cleanliness and ventilation were better. Similarly, in Manchester, Dr. John Ferrier in 1773 noted that the number of deaths from typhus was just twice that of the surrounding countryside. His belief was that overcrowding, old houses and narrow lanes were its main sources. This state of affairs led in 1796 to the establishment in Manchester of a fever hospital, which, apart from plague hospitals, was the first to be reserved for this purpose. A new awareness of the need to prevent the spread of disease was developing, although it was realised that the relative isolation of the British Isles protected the population from epidemics, except from diseases brought back by those who travelled, fought wars or engaged in trade abroad. It is possible that legends of dreadful and unfamiliar diseases in foreign lands limited to some extent the scale of exploration, colonisation and voyages around the world.

The pattern of communicable disease is constantly undergoing change and since diseases move with people, they follow the routes of travel and trade. In this age the

* Presidential Address to the Medical Society of London for the Session 1967-68 delivered on Monday, 9 th October, 1967.

To be published in the Medical Society's Transactions Vol. LXXXIV in October, 1968. 
urge to travel is inherent in nearly everyone. It is probably correct to say that in the absence of preventive measures the greater the movement of population the more likely the spread of disease. Whether due to viruses, bacteria or parasites, some of these conditions are already endemic in Britain. Others are contracted only in countries towards the equator where the existing standards of hygiene are poorly developed. Many of these are animal infections communicated to man, an intermediate host being necessary in many instances.

Examples of the objects of travel are recreation, business and education. The dividing line between essential and non-essential journeys depends largely on motivation, occupation, necessity and ethnic reasons. School children, migrants, servicemen, air crews, seamen and missionaries are on the list of those who move from place to place. As a result of this change in environment each becomes exposed to new infections necessitating a degree of self-discipline. The result is modified by the measures of personal protection he follows, his adaptability, and any immunity he acquires by clinical or subclinical infection. The traveller is seldom aware of the health dangers he faces abroad, particularly in areas of special risk.

In Lettsom's day travel itself did not occasion many of the problems we now associate with it, and today in contrast with conditions in the 18th century, urban standards of public health are usually higher than rural ones. As the speed of travel increases man has greater difficulty in adjusting himself both mentally and physically to his new environment. Adaptation to climate, food, water, clothing and other factors in the new surroundings have to be made consciously or unconsciously by each traveller. However, it is possible to stay in a long chain of luxury hotels around the world without encountering any unfavourable circumstances. This can be an expensive pastime with little or no gain in active immunity against endemic diseases. Thus it has its limitations both in terms of medicine and economics.

Because of these facts we must take a fresh look at the problem of adaptation to the increasing speed of air travel. These difficulties will certainly grow as, for instance, air travel becomes still more rapid and sophisticated. As altitudes become higher and trips shorter, time zones are traversed more quickly. The effect of rapid changes of time on the body's circadian rhythm* is becoming better understood. The sequence of light and darkness plays an important role in exercising rhythmic control of man's adrenal secretion.

The barometric pressure of cabin altitudes in modern jet aircraft is in the 5 to 7,000 feet range, and it may on occasions reach 8,000 feet for short periods. The relative humidity is usually between 5 and 15 per cent at these altitudes. Although these levels can be regarded as safe, resulting subjective effects include dryness of eyes, nose, mouth and skin. Increased thirst and oliguria may be experienced and dehydration may play a part in causing venous thrombosis of the legs following long journeys. There is normally good air circulation in the cabin but ventilation may be badly distributed. The result of all these adverse environmental factors tends to be cumulative.

While on flying duty members of the crew of an aircraft are working at maximum activity and, in due course, many of them are likely to suffer from fatigue. This can be defined simply as "the ill-effect or deterioration of performance which results either

* This term is in current use to describe the physiological functions having a cyclic variation with a periodicity of about 24 hours. 


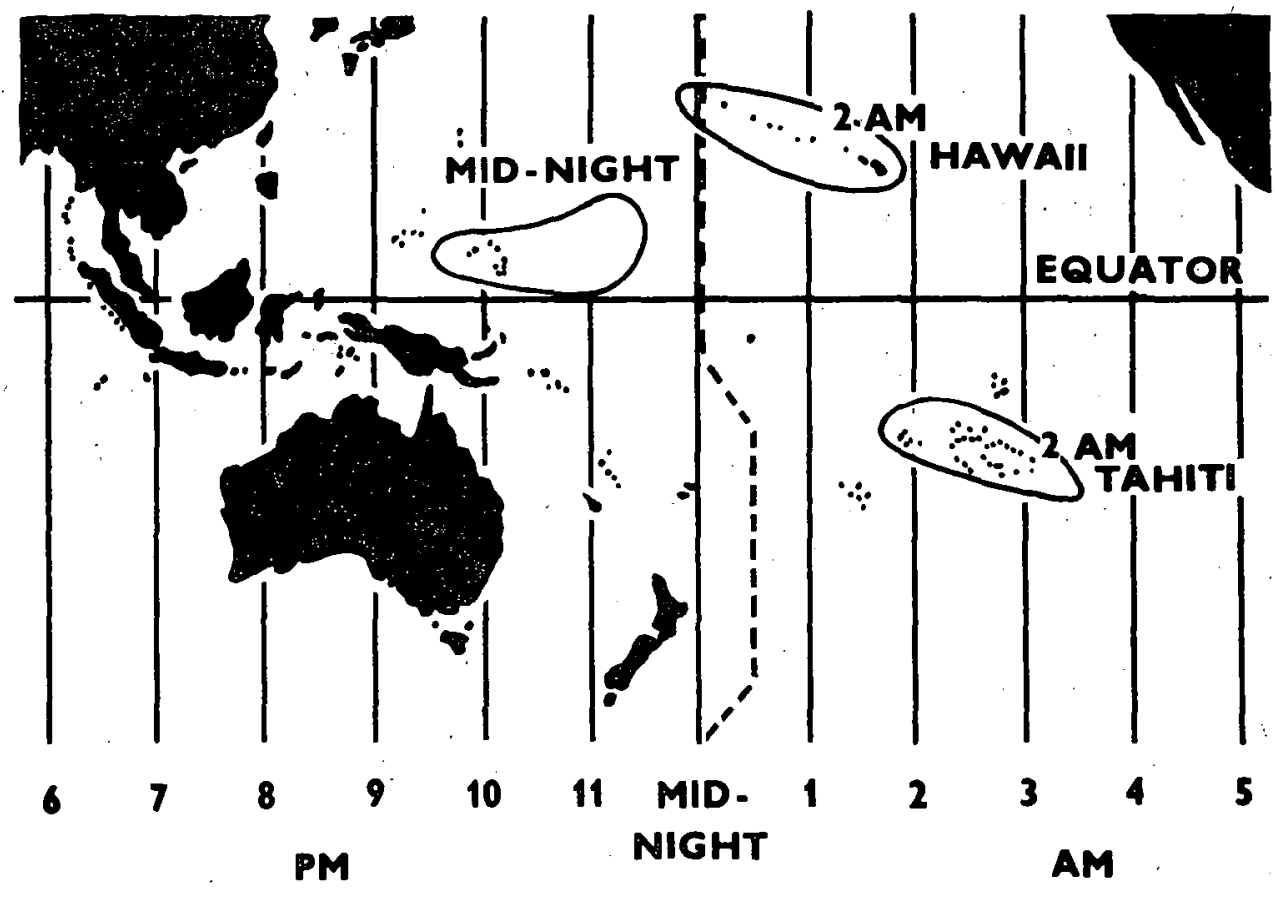

INTERNATIONAL DATE LINE - - - -

Fig. 1-Time Zones in the Pacific Area.

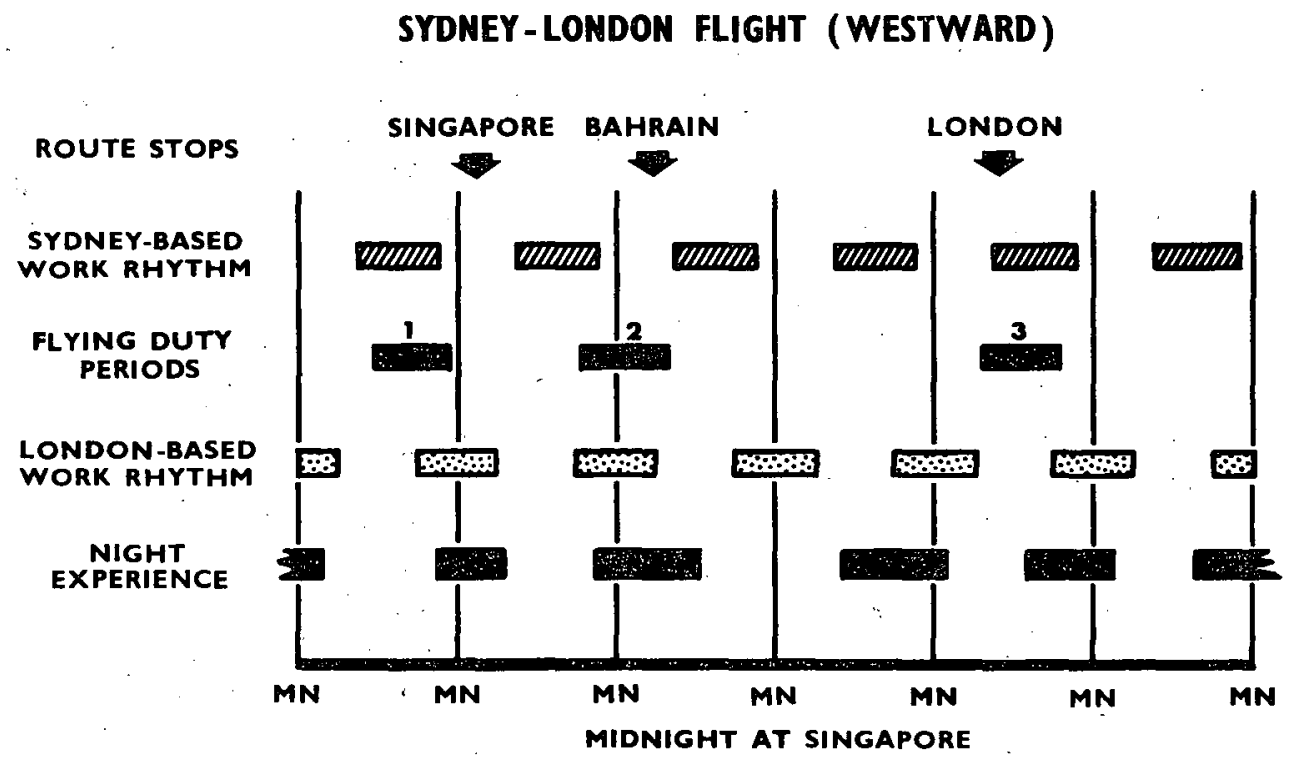

Fig. 2-A Pilot's Experience in Flying from Sydney to London (after Cumming (1966)). 
during or after normal operational activity". In contrast, the passengers are at rest and are either bored or indifferent to their surroundings and can often complete a series of short hops or=long hauls without adverse effect. On the other hand, aircrew may suffer from fatigue and uncertainty unless careful planning of their schedules is undertaken beforehand. There is no doubt that chronic stress and anxiety play a part in disturbing the individual's mental and physical equilibrium. The alteration in circadian rhythm is therefore likely to be reflected to a greater extent in crew than passengers. Since cabin pressurisation in modern jet aircraft is rarely complete some hypoxia is inevitable. This will have little effect on the young fit traveller, but in the elderly a degree of cerebral impairment or adverse effects on the heart may result on long flights. Following flights lasting more than six hours the passenger may suffer a phase of mental disturbance and lack of concentration. This difficulty may well be obviated by breaking the journey, thus ensuring an interval of suitable rest.

Flights to North and South involve little fatigue because the hours of daylight are not altered to any extent. Although air travel in either direction upsets the body's routine, journeys from West to East have a more marked effect than those Westwards. In other words, following the sun is kinder to the body's circadian pattern. Either way it is believed that as long as a week may then be required before normal physiological rhythm is restored. As a first step, one Aviation Authority has recently recommended that for crew and passengers at least twenty-four hours rest be compulsory after journeys by air of six hours or longer.

\section{The Travelling Population}

Last year more than five million British tourists took their holidays abroad. The most popular countries were Spain, Italy, France, Ireland, Germany, Switzerland and Scandinavia, in that order. A sizeable number visited the Mediterranean, Africa and North America. More than half of them travelled by air and their average length of stay abroad was two weeks.

In the same period, of the visitors who arrived in Britain, two million came from Europe, one million from North America, 100,000 from Australja and New Zealand, 90,000 from India, 80,000 from Africa and almost 100,000 from Central and South America. One wonders what bizarre diseases and exotic parasites these travellers brought with them. We do not know the risks to the rest of the community, or whether these conditions have since been recognised and treated effectively.

\section{Migration}

Immigration raises many problems. Perhaps we can accept with equanimity healthy newcomers from temperate climates, but the arrival of those from the tropical and subtropical zones raises language, housing and intregation difficulties. There are probably now more than a million coloured immigrants of whom half are West Indians, and the rest from India, Pakistan, Ceylon, Hong Kong and Africa. New arrivals at a current rate of around 50,000 a year are now mainly dependent women and children. Most of these coloured Britons have settled in large population centres like Birmingham, Bradford, Liverpool and London. Already they number about 1 in 50 of the population and the proportion is rising steadily.

Not surprisingly they have brought with them their local diseases, for example, 
malaria and parasitic conditions, such as hookworm, schistosomiasis and filariasis. In these races the character of these diseases may be quite different, and their presenting symptoms less marked, than in Europeans. Where the spread of disease is concerned personal habits and tribal customs are more important than the amount of pigment in the skin. Among coloured migrants there has been some venereal disease, enteric and dysentery and a few cases of leprosy. Eye conditions like trachoma and conjunctivitis have been plentiful, but the principal infection remains respiratory tuberculosis.

The overall annual incidence of tuberculosis in Britain has steadily declined to below thirty cases per 100,000 population, but in immigrants current rates for this disease may be summarised as:-

West Indians - Twice the rate in the British population
Indians - $\quad-$ Six times the rate in the British population
Pakistanis $\quad-$ Thirty times the rate in the British population

Abroad, however, the chance of acquiring pulmonary tuberculosis is considerably greater since it is one of the commonest of diseases in the tropics where unfortunately tuberculous infections are already showing developed drug resistance.

Particularly in immigrants from East and West Africa and the Caribbean Area, it is necessary to be on the watch for the haemoglobinopathies, especially sickle cell disease. Although this latter abnormality provides some hereditary protection against malignant malaria in their own countries, such individuals may develop infarcts, especially of the spleen; during their inward travel by air.

It is indeed fortunate that the Indian and Pakistani doctors currently employed in many hospitals in this country often understand these patients and their diseases better than their European counterparts.

\section{Virus diseases}

\section{The Pattern of Disease}

Of the internationally notifiable and quarantinable diseases, smallpox heads the list. It has already been discussed at some length-in this Society so I shall limit my remarks to recent developments. More than 60,000 cases of smallpox with 10,000 deaths were notified world-wide in 1966. Most came from Asia and Africa but these numbers must be far from complete. This year, because of epidemics in India, the incidence is certainly higher.

It is not surprising that the World Health Assembly last year embarked on a smallpox eradication programme based largely on effective vaccination. Methods of vaccination have greatly improved, the new lyophilized vaccine is stable, the multiple pressure technique has largely superseded the linear scratch method, and vaccination by jet is coming into use. Primary vaccination can most safely be carried out in the second year of life; contraindications to vaccination like pregnancy and chronic eczema are now better appreciated. International certification is becoming more reliable and it is generally realised that everyone working in a hospital is at great risk from imported smallpox.

The danger of atypical forms of smallpox being introduced into the United Kingdom at any time remains an obvious one. In 1966 there were 71 cases of smallpox in Britain. Most of these were variola minor and occurred in three separate epidemics. These outbreaks lasted for about six months altogether and one result was that the electron microscope was brought into use for rapid and early laboratory diagnosis. 
The chemotherapy of smallpox is now well established and oral methisazone (Marboran) has a firm place in the early treatment of contacts, who should nevertheless be vaccinated to protect them against further exposure to infection. Methisazone is now available in unlimited quantities in contrast to human anti-vaccinial gammaglobulin which gives protection but is in short supply.

The other pox diseases which already occur in this country are chickenpox, generalised vaccinia following vaccination, milker's cow-pox and orf. Orf, which is a disease of sheep, may be contracted by shepherds or shearers in whom it causes a pustular dermatitis. As many as six cases were reported in one week in the Spring of last year.

Another important virus disease from which we have so far been protected by international control measures is yellow fever. Today, mosquito-transmitted yellow fever is endemic in a broad belt across tropical Africa and in South America. Nearly all the 330 cases reported in 1966 were fatal. After being free from yellow fever for twelve years a serious epidemic occurred in Senegal, which accounted for most of the infections reported in 1966. A valid international certificate of vaccination against yellow fever is required by travellers through the recognised yellow fever zones in Africa and America.

The frequent occurrence of infective hepatitis the world over is causing great concern. Britain has an attack rate of about 20 per hundred thousand with about 300 deaths annually compared with a much greater incidence in North Africa, the Far East and the Pacific Area. Until more is known about the causative organism and its mode of transmission, little progress will be made in prevention. Recent work has cast doubt on the prophylactic use of human gammaglobulin. Although this confers a degree of individual protection it is still possible for subclinical hepatitis to develop and for the infection to be transmitted to others. Solutions to these various problems are eagerly awaited.

Rabies, with its long incubation period in man, we must expect to see here occasionally. In the past twelve years there have been four deaths from this disease in Britaintwo servicemen, a Pakistani and, recently, an Indonesian. The quarantine imposed on animals entering the British Isles does protect us, but in the last two years in spite of it, a labrador dog and a leopard cub have died here of rabies, necessitating anti-rabic treatment for a number of human contacts. Abroad, rabies is common in animals; for instance, in a recent year in Italy nearly 5,000 people were bitten or licked by known rabid animals. Children, because of their tendency to play with dogs and cats, are at special risk. Each year we must expect an inflow of persons who may well have been licked or bitten by an animal suspected of rabies and the question of giving prophylactic vaccine will then arise. To be effective this preventive treatment must be given early and the small risk of a major paralytic accident ( 1 in 6,000 persons so treated) must be taken and accepted.

Of small but definite importance are various forms of encephalitis due to Japanese B or other arboviruses. These may be contracted abroad especially in the Far East and first manifested after arrival here by air.

\section{Bacterial diseases}

Gastro-intestinal infections apart, the bacterial group of diseases is becoming controlled at a satisfactory rate. Cholera, the main offender, is for the first time since 1922 threatening Europe. The pandemic which began in the Philippines six years ago and soon spread throughout the Far East has continued its relentless march through to the Middle 
East. This time the offending organism is the Vibrio el tor causing a type of cholera which gives rise to many symptomless carriers and tends to become widespread in families and households. With its short incubation period cholera could readily be introduced into Britain, but it is doubtful that with our waterborne sanitation it would spread to any extent. Today public health authorities are on the alert and for international travel a valid certificate of vaccination against cholera is almost as necessary as a passport.

The salmonella group of bacteria which are excreted by many domestic animals are constantly contaminating our food. For example, it is only a few months since Salmonella typhimurium was an unexpected guest at Lancaster House, with devastating results. Lately enteric infections have been reduced to a trickle, but Zermatt, Aberdeen and infected corned beef are still fresh in our memories. One good result is that standards of hygiene in the meat canning industry overseas have already improved. In spite of the introduction of ampicillin for treatment the typhoid carrier still limps her way sporadically through our midst.

We need no reminder that bacillary dysentery, that real bane of travellers, is all too common, for more than 30,000 cases were reported here last year. On short trips abroad the taking of various preparations to prevent it probably do less harm than good, but they are no substitutes for proper standards of hygiene and sanitation.

On farms in Britain brucellosis continues to menace the dairyman and his family, but since the disease is not notifiable its incidence cannot be accurately assessed. Although in Britain 30 per cent of the herds of cattle are believed to be infected, overseas, especially in the Middle and Far East, goats, pigs and sheep greatly increase the chance of infection with this group of organisms. Brucellosis is now recognised as a risk veterinarians must take, and in the general population it is proving to be a more frequent cause of joint disease than was formerly supposed.

With nearly 400 lepers in Britain and more than 2 million world-wide it is good news that the horizon for the sufferer from leprosy is becoming brighter. There is now good evidence that after a few months treatment with dapsone all forms of leprosy become non-infective. The patient under treatment is therefore able to lead a normal life. The susceptible child contact can now be protected successfully by B.C.G. vaccination and by taking regular small doses of dapsone.

Today, diseases in which rodents are involved, for example, bubonic plague and typhus fevers are of little moment except in Africa, the Far East and South America. Last year, however, more than 3,000 cases of plague occurred in Vietnam and it should always be remembered that the rat in search of his food rivals man as a traveller.

\section{Protozoal Diseases}

Among protozoal diseases malaria merits the greatest attention. As a major cause of ill-health and anaemia in tropical and sub-tropical areas, malaria is receiving priority in eradication programmes in most of the countries concerned. The war in Vietnam has stimulated a vast programme of research which is at last beginning to achieve results. In 1967 more than 8,000 cases of malaria occurred there in American soldiers, and, in spite of chemoprophylaxis with chloroquine, more than 1,000 returned servicemen developed malaria in the United States in the first three months of that year.

Plans to control and eradicate malaria are being implemented in many countries. These consist of the use of chemical insecticides in the form of residual sprays to destroy adult mosquitoes in huts and houses, combined with mass administration to local 
inhabitants of anti-malarial drugs, sometimes added to their table salt. Unfortunately, many mosquito vectors have already developed resistance to insecticides, the range of which, thanks to the chemical industry, increases yearly. The new lines of attack are ingenious methods of biological and genetic control of the insect vector which are apparently not only effective but tend to be self-perpetuating.

Recognition that the malarial parasites themselves are capable of developing drug resistance was first made in British soldiers serving in Malaya and this has now been confirmed in many countries. Fortunately, a number of new drugs being developed and screened for their therapeutic effect on the parasites are proving effective.

Studies of immune reactions in human and animal malaria have led to a better understanding of the disease, and many aspects of its pathology, especially of falciparum malaria, are becoming clarified. In spite of an inflow of patients with malaria into Britain, the majority have only simple tertian infections. On the other hand, a few show malignant tertian or falciparum malaria, which constitutes a medical emergency of the first order. It should not be forgotten that an unexpected encounter with an infected mosquito on a refuelling air stop may unwittingly give rise to cerebral malaria. As a rule, time to avert a fatal issue is short and treatment with either intravenous quinine or chloroquine must not be unduly delayed. Once malaria is suspected, whenever possible the patient should be in hospital with all diagnostic aids to hand.

Regular and prolonged chemoprophylaxis is strongly advised for all who enter malarious countries. This must be continued until four weeks after their return to a malaria-free area. In British practice proguanil is used for this purpose, but elsewhere weekly chloroquine is still being taken. This latter drug may give rise to many problems among which are, on the one hand irreversible retinal damage and, on the other, parasite resistance. Long-acting suppression using repository drugs is under investigation and is already showing promise. Treatment of the disease has changed little except that sulphones have been introduced for the treatment of relapsing vivax malaria. Some trials with oral long-acting sulphonamide-pyrimidine combinations have been carried out.

Among other protozoal diseases are leishmaniasis, trypanosomiasis and amoebiasis, all of which may remain latent before symptoms develop. In the British Army about 100 soldiers have been found lately to have visceral or cutaneous leishmaniasis some months after completing tours of duty in the Arabian Peninsula. This occurrence has tended to exaggerate in our minds the possibility of an inflow of cases of this disease from other parts of the world, and is apt to confuse the more likely diagnosis of malaria. Trypanosomiasis or sleeping sickness can be acquired by the bite of the tsetse fly in a limited part of Africa, and is therefore likely to be a rarity in Britain.

Amoebiasis is quite a different problem. About 10 per cent of the population of this country harbour Entamoeba histolytica in a non-pathogenic commensal form which only rarely induces clinical amoebiasis. In contrast, this protozoal parasite when acquired abroad tends to be pathogenic and latent causing chronic amoebic dysentery. Provided this disease is kept in mind, an experienced protozoologist will soon make or exclude it by stool examination. On the other hand, hepatic amoebiasis presenting with signs at the base of the right lung can be difficult to differentiate. Recent valuable developments in connection with amoebiasis include the use of an indirect fluorescent antibody test for diagnosis, and for treatment the substitution of dehydroemetine salts for those of emetine itself with less tendency to produce myocardial changes. 


\section{Helminthic Diseases}

We now come to a consideration of the parasitic worms harboured by man. Since it has been estimated that the total number of individual infestations exceeds the earth's population, multiple helminths must be common in a large number and especially in the inhabitants of Asia. It is not therefore surprising that the 700 million Chinese are believed to excrete 25,000 tons of hookworm ova annually.

Perhaps before being critical of other countries we should take steps to eliminate a helminth which is, so to speak, on our own doorstep. I refer to the common round worm of dogs and cats of which more than 20 per cent are affected in London alone. It has been pointed out that toxocariasis may be responsible in children for many more serious conditions than was previously realised.

Because of our methods of sewage disposal it is unlikely that ordinary worms like Ancylostoma and Ascaris will ever gain ground in this country. Nevertheless, a number of immigrants are found to be harbouring these and other intestinal helminths.

Of the worm diseases due to invasion of tissues only Schistosomiasis and Filariaris are, as a result of immigration, now frequent in Britain. Schistosomiasis not only causes damage to the urinary and intestinal tracts but is responsible for much ill-health in Africa and Asia. The patients seen here usually show the results of repeated re-infections and accordingly chemotherapy gives less favourable results than in early cases.

On visiting South East Asia and the Pacific area one can readily believe that more than 200 million people there suffer from filariasis. Of the many variations in the manifestations of these diseases onchocerciasis in tropical Africa is important because it may cause blindness. In the early stages all forms of filariasis respond well to treatment with diethylcarbamazine. Although curative treatment is relatively satisfactory, control of these diseases remains a tremendous problem depending in most instances on elimination of the insect vector concerned.

\section{Travel and Health}

With certain diseases the risks are limited to the traveller alone but with others their introduction to this country may become a risk to the community at large. An added danger with today's swift travel is that he may be only incubating this latter type of disease when he returns to his home base.

Before setting out to face this cavalcade of diseases careful planning of journeys is essential. Accordingly, by the time our traveller arrives overseas he will already be immune to some diseases and be protected by chemoprophylaxis from others. Nevertheless, in order to remain well throughout his tour abroad he must be on his guard continually and follow at all times the commonsense advice on health given by his doctor at home. He could with advantage be told to purchase a small handbook on personal hygiene in warm climates to reinforce these recommendations. After all, such publications have been around for a long time. Probably the first was written by Moses-he called it the Book of Deuteronomy-and in it gave simple instructions on the preservation of health during a journey, all in their way as pertinent today as they were then.

It is almost two hundred years since the concept of healthy travel really began to develop. In 1771, James Cook returned from his famous scientific expedition to the South Seas. He had set out in H.M.S. Endeavour with a company of 85 men three years before, but by the time he reached home they had been decimated by dysentery, malaria 
and ill-nourishment. Among other observations he noted that most diseases developing at sea had usually been acquired on land.

Soon Cook was planning his second expedition, determined not to repeat such calamitous losses. In H.M.S. Resolution he sailed with a complement of 112 men from Plymouth Sound on 13th July, 1772, so that he was already in New Zealand when this Society held its first meeting. A combination of strict discipline, careful attention to hygiene and a balanced diet enabled them to complete this voyage, which lasted three years and eighteen days, with the loss. of only one man from disease. On his return home Cook reported to the Admiralty as follows:-

"Whatever may be the public judgment about other matters, our having discovered the possibility of preserving health among a numerous ship's company for such a length of time, in such varieties of climate and amidst continued hardships and fatigues, will make this voyage remarkable in the opinion of every benevolent person." The award of the Copley Gold Medal of the Royal Society to Captain James Cook, F.R.S., R.N., was proof of this testimony.

Prolonged voyages such as these have over the centuries shown the importance of preventive medicine. The recent epic voyage of Sir Francis Chichester is another case in point, although here the main emphasis was on isolation, privations and the stresses and strains of the sea.

Thanks to these and many other pioneers, land, sea and air as well' as space itself have now become the happy hunting ground for international travellers. Alas, much still remains to be done in the application of preventive medicine internationally, nationally and by individuals themselves.

\section{Conclusion}

This evening I have attempted to relate disease and travel, yet nearly three hundred years ago a journey in allegory was described as follows:-

"It happens to us, as it happeneth to Way-fairing men; sometimes our way is clean, sometimes foul; sometimes up-hill, sometimes down-hill; We are seldom at a Certainty. The Wind is not alwayes on our Backs, nor is every one a Friend that we meet with in the Way."

I wonder if the basic problems of those who travel have changed to any great extent.

\section{REFERENCES}

Abraham, J. Johnston (1933). Lettsom. Wm. Heinemann Medical Books Ltd., London.

Bunyan, J. The Pilgrim's Progress, Second Part, p. 275. The Clarendon Press, (1960 Ed.). Oxford.

Cumming, R. W. (1966). Aircrew Fatigue. Paper given at the International Meeting on Aerospace Medicine, 28th Nov.-1st Dec., 1966. Sydney Australia.

SEMple, A. B. (1967). The Health and Care of Immigrants. Paper given at the International Health Conference, The Hague, 5th-9th Sep., 1966. The Royal Society of Health, London.

Stoll, N. R. (1947). J. Parasit. 33, 1.

THROWER, W. R. (1951). Lancet, ii, 215.

Wil cocks, C. (1967). Abstr. Wld Med. 41, 241.

Wilcocks, C. (1967). Abstr. Wld Med. 41, 325.

WoOdruff, A. W., Bisseru, B. and Bowe, J. C. (1966). Brit. med. J. i, 1576.

\section{Society of Medical Officers of Health}

Major-General R. A. Smart, C.B.E., M.B., M.R.C.P., D.P.H., Director of Army Health, has been nominated President of the Services Group of the Society of Medical Officers of Health for coming year commencing 23rd February, 1968. 